\title{
Pharmacy Benefit Spending on Oral Chemotherapy Drugs
}

\author{
FREDERIC R. CURTISS, PhD, RPh, CEBS
}

\begin{abstract}
BACKGROUND: Pharmacy benefits have historically excluded injectable drugs, resulting in coverage of injectable drugs under the medical benefit. High-cost biologics and other new drug therapies are often injectables and therefore have not presented cost threats to pharmacy benefits. The U.S. Food and Drug Administration approval of capecitabine, an oral form of fluorouracil, in 1998, and imatinib mesylate in oral dose form for chronic myeloid leukemia, in 2001, signaled a new period in budget forecasting for pharmacy benefits, particularly for small, self-insured employers for whom a drug with a cost of $\$ 25,000$ per year of therapy for 1 patient could increase total pharmacy benefit costs by $10 \%$ or more.
\end{abstract}

OBJECTIVE: To quantify the actual relative costs of the oral chemotherapy drugs in pharmacy benefits in $\mathbf{2 0 0 6}$ and identify the history of spending on oral chemotherapy drugs relative to total pharmacy benefit spending for small, self-insured employers over the 4.5 years through May 2006.

METHODS: Administrative pharmacy claims from the database of a pharmacy benefits manager (PBM) for approximately 500,000 members of small, self-insured employer plans were used to calculate the net plan cost of oral chemotherapy drugs relative to total drug benefit costs for the period January 1, 2002, through May 31, 2006. Current costs for oral chemotherapy drugs for small employers were compared with an insured health plan of approximately the same number of members for dates of service January 1, 2006, through May 31, 2006.

RESULTS: This descriptive analysis found that oral chemotherapy drugs represented $0.27 \%$ of total drug benefit costs, or approximately $\$ 0.08$ per member per month (PMPM) for small, self-insured employers in 2002 , rising linearly to $0.73 \%$, or approximately \$0.24 PMPM in the first 5 months of 2006. Members in pharmacy benefit plans sponsored by small employers paid an average $6.9 \%$ cost share for oral chemotherapy drugs in 2006 , nearly identical to the average $8.5 \%$ paid by members of an insured health plan of similar size in total membership, versus $26.9 \%$ average cost share for all drugs. Imatinib mesylate accounted for $45 \%$ of total spending on oral chemotherapy agents in 2002 versus $40 \%$ in 2006 .

CONCLUSION: Spending on oral chemotherapy drugs as a proportion of total pharmacy benefit costs has more than doubled, from about $0.3 \%$ in 2002 to $0.7 \%$ in 2006. For small, self-insured employers, this represents a nearly 3-fold increase in spending, from about \$0.08 PMPM in 2002 to about \$0.24 PMPM in 2006.

KEYWORDS: Pharmacy benefits, Budget forecasting, Chemotherapy drugs, Drug costs

J Manag Care Pharm. 2006;12(7):570-77

\section{FREDERIC R. CURTISS, PhD, RPh, CEBS, is editor-in-chief, Journal of}

Author Managed Care Pharmacy, Academy of Managed Care Pharmacy, Alexandria, Virginia.

AUTHOR CORRESPONDENCE: Frederic R. Curtiss, PhD, RPh, CEBS, Editor-in-Chief, Journal of Managed Care Pharmacy, Academy of Managed Care Pharmacy, 100 North Pitt St., Suite 400, Alexandria, VA 22314. Tel: (830) 935-4319; Fax: (703) 683-8417; E-mail: fcurtiss@amcp.org

Copyright $\odot 2006$, Academy of Managed Care Pharmacy. All rights reserved.
$\mathrm{T}$ he U.S. Food and Drug Administration (FDA) approved lenalidomide (Revlimid), an analogue or derivative of thalidomide, on June 29, 2006, for use in combination with dexamethasone in patients with multiple myeloma who have received 1 prior therapy. ${ }^{1}$ Its manufacturer immediately made headline news by announcing that it would price the chemotherapy agent at $\$ 6,195$ per month, which extrapolates to a drug cost in excess of $\$ 74,000$ per patient per year of therapy. ${ }^{2}$ This was not lenalidomide's first approval, however. The FDA had approved it on December 27, 2005, for the treatment of transfusion-dependent anemia due to myelodysplastic syndrome (MDS); for that indication, it was dosed at $10 \mathrm{mg}$ per day with downward dose adjustment for patients experiencing thrombocytopenia. ${ }^{3}$ The manufacturer's pricing structure appeared different for the 2 indications.

When the FDA approved the second indication, lenalidomide's average price per patient per year increased by about $35 \%$, from $\$ 55,000$ for 12 months of therapy for anemia associated with MDS to $\$ 74,000$ per patient per year for the second, more common indication, multiple myeloma. While the dose for multiple myeloma is $25 \mathrm{mg}$ per day (two-and-one-half times higher than the starting MDS dose), some Wall Street analysts criticized the pricing of lenalidomide for multiple myeloma because (a) its annual cost far exceeds that of other antineoplastic agents, (b) its production costs should be lower since it is not a biologic agent and is an oral as opposed to an injectable dosage form, and (c) excessive pricing would likely invoke Congressional scrutiny due to its potential financial impact on Medicare and Medicaid programs.

\section{Capecitabine Marks New Era of Oral Antineoplastics}

A few oral antineoplastics have been available for decades; most of these have been relatively inexpensive. The new world of high-cost oral chemotherapy began in the United States when the FDA approved capecitabine (Xeloda), an oral form of fluorouracil, on April 30, 1998, for the treatment of advanced breast cancer resistant to paclitaxel in combination with an anthracycline such as doxorubicin ${ }^{4}$ (Table 1 ). Three years later, and despite the fact that "cancer" is a collection of diverse diseases, results from clinical trials of imatinib mesylate triggered hopes that not only was a cure for cancer possible but also that the treatment could be administered by mouth.

\section{Imatinib Mesylate}

At the annual meeting of the American Society of Hematology in early 2001, the results from three phase 3 clinical trials were presented for STI571, a tyrosine kinase inhibitor. One clinical 
Pharmacy Benefit Spending on Oral Chemotherapy Drugs

\begin{tabular}{|c|c|c|c|}
\hline Mercaptopurine & Purinethol & September 11, 1953 & Multiple neoplasms \\
\hline Capecitabine & Xeloda & April 30, 1998 & Breast cancer; colorectal cancer \\
\hline Imatinib mesylate & Gleevec & May 10, 2001 & Chronic myeloid leukemia \\
\hline Sorafenib & Nexavar & December 20, 2005 & Advanced renal cell carcinoma \\
\hline Sunitinib malate & Sutent & January 26, 2006 & GI stromal tumor; advanced renal cell carcinoma \\
\hline Thalidomide & Thalomid & May $26,2006 \dagger$ & $\begin{array}{l}\text { Multiple myeloma-in combination with dexamethasone, } \\
\text { for the treatment of patients with newly diagnosed multiple } \\
\text { myeloma }\end{array}$ \\
\hline Lenalidomide & Revlimid & June $29,2006 \ddagger$ & $\begin{array}{l}\text { In combination with dexamethasone for the treatment of } \\
\text { multiple myeloma patients who have received at least } \\
1 \text { prior therapy }\end{array}$ \\
\hline \multicolumn{4}{|c|}{$\begin{array}{l}\text { * These drugs are identified by Medi-Span Generic Product Indicator (GPI) beginning with 2153, or } 9939 \text { or } 2130 \text { (except not GPI beginning with } 213000501 \\
\text { [methotrexate], which is standard treatment for several indications, including rheumatoid arthritis and psoriasis, in addition to use as an antineoplastic agent). } \\
\text { † Thalidomide previously approved by the FDA on July 16, 1998, for acute and maintenance therapy for erythema nodosum leprosum. } \\
\text { ₹ Lenalidomide previously approved by the FDA on December 27, 2005, for the treatment of patients with transfusion-dependent anemia due to low-or inter- } \\
\text { mediate-1 risk MDS associated with a del } 5 q \text { cytogenetic abnormality with or without additional cytogenetic abnormalities. } \\
\text { FDA=U.S. Food and Drug Administration; GI= gastrointestinal; MDS=myelodysplastic syndrome. }\end{array}$} \\
\hline
\end{tabular}

trial involved 500 chronic phase patients with chronic myelogenous leukemia (CML) who had failed to respond to interferon therapy. CML is characterized by translocation of chromosome material from chromosome 9 to chromosome 22 with formation of the so-called Philadelphia chromosome. After 6 months, greater than 90\% of STI571-treated patients had white cell counts return to normal range and half had a significant reduction of Philadelphia chromosome-positive cells. ${ }^{5}$ In a second study of 154 CML patients who had received STI571 for at least 1 month, 78\% had a hematology response and 14\% (22 patients) experienced disease remission. A third trial involving 94 patients in blast crisis (end-stage CML) showed a $47 \%$ response rate after 2 months of therapy with STI571. The researchers speculated that the combination of STI571 and cytosine arabinoside (Ara-C) or interferon could one day produce a cure for CML. Stem cell (bone marrow) transplant remains the only known cure for CML. ${ }^{6}$

The manufacturer sought fast-track approval in Europe and the United States, describing STI571 as a "smart" drug that disables only the abnormal protein that causes CML without affecting normal cells. In March 2001, STI571 was expected to be approved by the FDA as early as fall $2001 .^{7}$ In fact, the FDA approved STI571 (imatinib mesylate) in May 2001, just 3 months after the fast-track approval request, with a proprietary name change from the already-approved European name Glivec to Gleevec. ${ }^{8}$

The manufacturer marketed imatinib mesylate in June 2001 at an initial $\$ 19.68$ average wholesale price (AWP) per $100 \mathrm{mg}$ capsule, resulting in an annual cost in the range of $\$ 29,000$ to $\$ 57,500$ per patient when dosed in the recommended range of $400 \mathrm{mg}$ to $800 \mathrm{mg}$ per day. Nine months later, the FDA approved imatinib mesylate for the additional indication of inoperable or metastatic malignant gastrointestinal stromal tumors (GIST). ${ }^{9}$ The GIST indication represented a significant advance in pharmacological treatment: until then, GIST had responded extremely poorly to polychemotherapy, and patients with inoperable GIST had extremely poor prognoses. Imatinib mesylate became the first effective treatment for GIST. ${ }^{10}$

Imatinib mesylate is now approved for the treatment of patients with all 3 stages of CML—myeloid blast crisis, accelerated phase, and chronic phase-either before or after other therapy, and GIST. ${ }^{11}$ Its dosage form has been redesigned for patient convenience, and it is now available as $100 \mathrm{mg}$ scored tablets and $400 \mathrm{mg}$ tablets. 


\section{FIGURE 1 Proportion of Total Pharmacy Benefit Spending for Oral Chemotherapy Drugs}

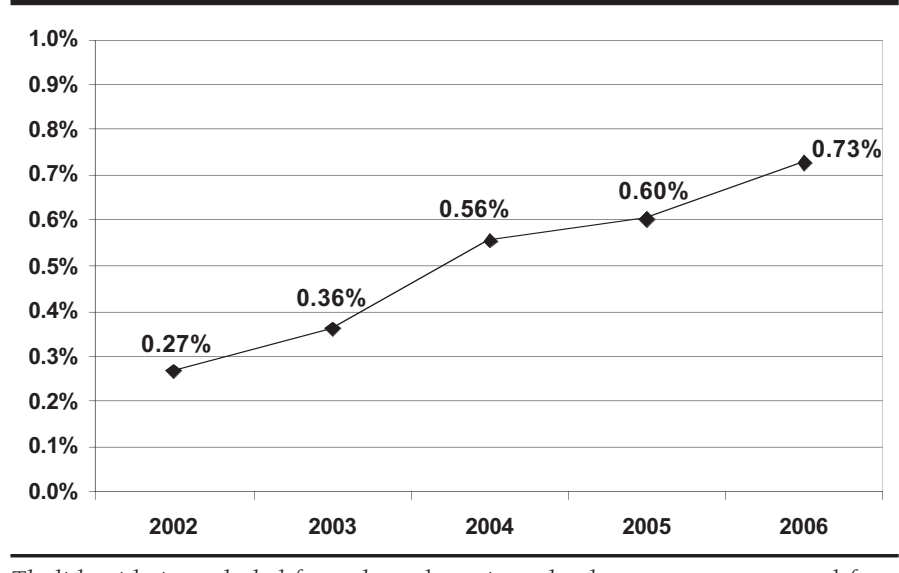

Thalidomide is excluded from these data since the drug was not approved for a cancer indication until May 26, 2006; summary data for claims with dates of service from January 1, 2002, through May 31, 2006, for more than 2,000 small, self-insured employers.

\section{Gefitinib}

On May 5, 2003, the FDA approved gefitinib (Iressa) for treatment of non-small cell lung cancer (NSCLC), dosed as a $250 \mathrm{mg}$ tablet with or without food; higher doses do not improve response but do increase toxicity.12 Two large trials involving 2,130 chemotherapy-naïve patients with stage III and IV NSCLC showed that gefitinib failed to improve tumor response rates, time to progression, or overall survival, when dosed at either $250 \mathrm{mg}$ or $500 \mathrm{mg}$ per day in combination with platinumbased chemotherapy regimens. The chemotherapies given in these first-line trials were gemcitabine and cisplatin $(n=1,093)$ or carboplatin and paclitaxel $(n=1,037)$. Subsequent to the release of the findings from these 2 large clinical trials, the FDA asked the manufacturer to relabel gefitinib to restrict it to monotherapy for treatment of patients with locally advanced or metastatic NSCLC after failure of both platinum-based and docetaxel chemotherapies. ${ }^{13}$ On June 17, 2005, the FDA approved new labeling for gefitinib for use only in patients who have demonstrated benefit from receipt of the drug. ${ }^{14}$ As part of the new labeling, distribution of gefitinib is restricted under a risk management plan called the Iressa Access Program. Gefitinib's effectiveness had been determined from objective response rates, and no controlled trials have demonstrated clinical benefit (e.g., improved disease-related symptoms or increased survival). Off-label use of gefitinib includes treatment of squamous cell head and neck cancer.

\section{Erlotinib}

Erlotinib (Tarceva) was first approved by the FDA on November 18, 2004. Erlotinib inhibits intracellular phosphorylation of tyrosine kinase associated with the epidermal growth factor receptor (EGFR), and further work is under way to completely characterize its mechanism of action. ${ }^{15}$ Like gefitinib, erlotinib is approved as monotherapy for patients with locally advanced or metastatic NSCLC after failure of at least 1 prior chemotherapy regimen. It is not approved, however, for first-line therapy, since 2 multicenter, placebo-controlled, randomized, phase 3 trials showed no clinical benefit when erlotinib was combined with platinum-based chemotherapy (carboplatin and paclitaxel, or gemcitabine and cisplatin) as first-line treatment of patients with locally advanced or metastatic NSCLC. ${ }^{16}$ On November 2, 2005, the FDA approved the second indication for locally advanced, unresectable, or metastatic pancreatic cancer in combination with gemcitabine..$^{17}$ Unlike gefitinib, erlotinib's effectiveness has been proven in randomized, controlled trials. ${ }^{18}$

\section{Sorafenib and Sunitib Malate}

The FDA approved 2 additional oral agents, sorafenib (Nexavar) on December 20, 2005, ${ }^{19}$ and sunitinib malate (Sutent) on January 26, 2006. ${ }^{20}$ Sorafenib, a multikinase inhibitor that decreases tumor cell proliferation, was approved for advanced renal cell carcinoma (RCC). Dose instructions include expected skin toxicity and consequent dose reductions to $50 \%$ or $25 \%$ of the initial recommended dose of $400 \mathrm{mg}$ (two $200 \mathrm{mg}$ tablets) twice daily. ${ }^{21}$ Sunitinib malate, which inhibits multiple receptor tyrosine kinases, was approved for GIST after disease progression or imatinib mesylate intolerance. Concurrent FDA approval for the indication RCC was based on partial response rates and duration of responses since there are no randomized trials of sunitinib malate demonstrating clinical benefit, such as increased survival or improvement in disease-related symptoms in RCC. ${ }^{22}$

\section{Thalidomide}

On May 26, 2006, the FDA approved thalidomide (Thalomid) under expedited review for the indication of newly diagnosed multiple myleoma patients in combination with dexamethasone..$^{23}$ Despite a preapproval, U.S. market withdrawal decades earlier for teratogenicity identified in postapproval European markets, thalidomide had been reintroduced to the U.S. market on July 16, 1998, when the FDA approved an indication for erythema nodosum leprosum (ENL; a complication of leprosy). ${ }^{24}$ Thalidomide's wide range of off-label uses include treatment of graft-versus-host disease after bone marrow transplantation, refractory multiple myeloma, primary brain tumors, appetite stimulant for cachexia in advanced cancer or human immunodeficiency virus (HIV)/acquired immunodeficiency syndrome (AIDs), aphthous ulcers, and prostate cancer in combination with docetaxel. ${ }^{25}$

\section{Dasatinib}

The FDA approved dasatinib (Sprycel) on June 28, 2006, for use in the treatment of adults with chronic phase, accelerated 
phase, or myeloid or lymphoid blast phase CML with resistance or intolerance to prior therapy, including imatinib mesylate. ${ }^{26}$ The expedited approval requires additional follow-up data to be converted to regular approval by the FDA. The FDA granted regular approval to dasatinib for use in the treatment of adults with Philadelphia chromosome-positive acute lymphoblastic leukemia with resistance or intolerance to prior therapy.

\section{Lenalidomide}

The first FDA approval of lenalidomide was on December 27, 2005, for myelodysplastic syndrome (MDS), characterized by hyperactive bone marrow but low blood cell counts. ${ }^{27}$ While the colony-stimulating factors such as filgrastim are used off-label for MDS, lenalidomide is the only oral drug approved by the FDA for MDS. Other drugs for MDS are injectables such as azacitidine (Vidaza), approved by the FDA on May 19, 2004. ${ }^{28}$ The Myelodysplastic Syndromes Foundation, sponsored by the manufacturers of drugs for MDS, includes on its Web site patient information for Medicare Part D and a Web link to find drug formulary coverage for MDS chemotherapy. ${ }^{29}$

\section{Methods}

The present study was precipitated in part by the pharmacoeconomic work by Ramsey et al. who earlier this year found a seemingly small budget impact from the coverage of erlotinib as a formulary drug, for 1 indication, NSCLC. ${ }^{30}$ The estimated budget impact of $\$ 0.01$ per member per month in a hypothetical health plan of 500,000 members could be consequential in a small employer health plan of 500 members, particularly if the pharmacy benefit is self-insured. Second, 5 new FDA approvals for high-cost oral chemotherapy drugs in 7 months through June 30, 2006, creates the need for descriptive, benchmark analysis of the actual direct pharmacy benefit costs for oral chemotherapy drugs.

Data for this study were obtained from 2 sources: the administrative pharmacy claims in the database of a pharmacy benefits manager (PBM) for approximately 500,000 members from more than 2,000 small, self-insured employers (2 to 5,000 members each) and an insured health plan with approximately 520,000 members. The PBM serves members nationwide, and the insured health plan is located in the southern United States. The net plan cost of oral chemotherapy drugs relative to total drug benefit costs was calculated for the period from January 1, 2002, through May 31, 2006, for the small employer drug plans. Current costs in 2006 for oral chemotherapy drugs for small employers were compared with the insured health plan for dates of service from January 1, 2006, through May 31, 2006. These oral chemotherapy drugs were identified by Medi-Span Generic Product Indicator (GPI) starts with 2153 or 9939 or 2130 (except not GPI starts with 213000501 [methotrexate, which has indications such as rheumatoid arthritis and psoriasis in addition to use as a antineoplastic agent]), and all but oral

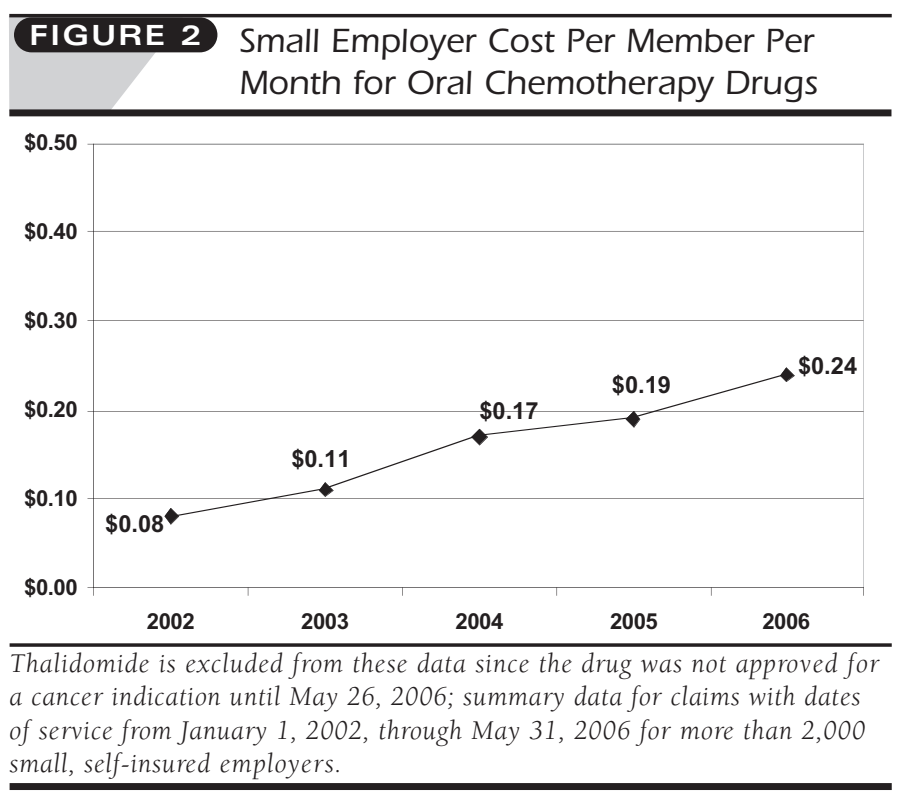

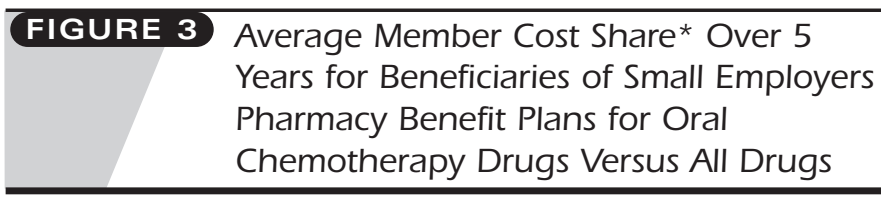

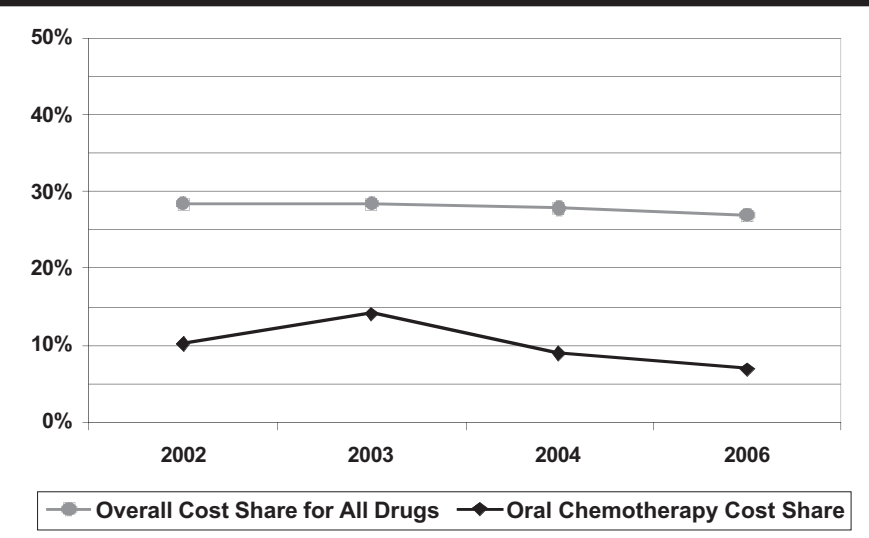

* Member cost share is the sum of all out-of-pocket costs at the point of service, including pharmacy benefit deductibles, benefit maximums, copayments, and coinsurance.

dose forms were excluded

Drug cost is defined from the payer perspective as the allowed charge less the member cost share (sum of deductibles, copayments, and coinsurance); hence, unless otherwise noted, drug cost is the net plan cost after subtraction of member cost share. Allowed charge is the sum of the allowed (discounted) drug ingredient cost plus the allowed pharmacy professional fee. Days of drug therapy is the sum of the days supply submitted 


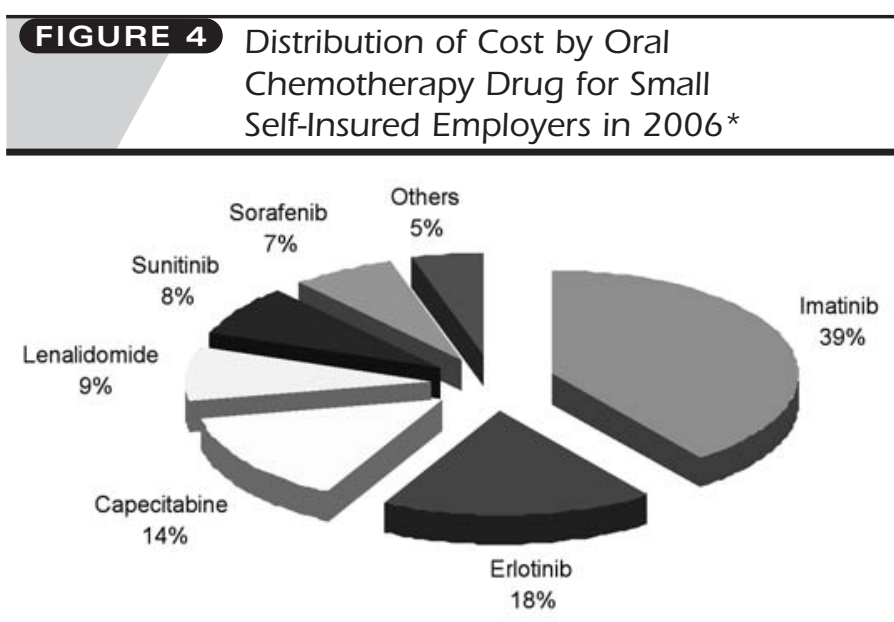

Thalidomide is excluded from these data since the drug was not approved for a cancer indication until May 26, 2006; summary data for claims with dates of service from January 1, 2002, through May 31, 2006 for more than 2,000 small, self-insured employers.

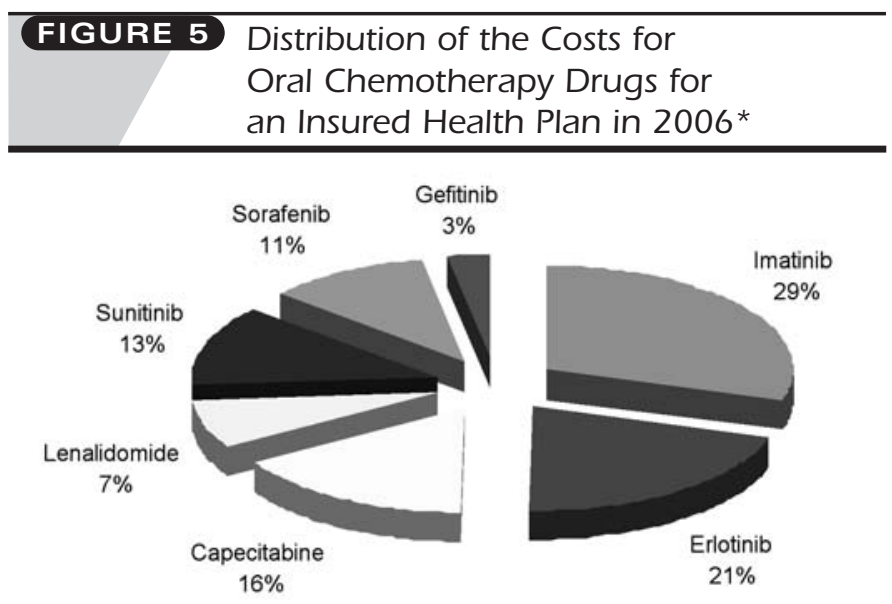

* Pharmacy claims with dates of service from January 1, 2006, through May 31, 2006.

on pharmacy claims. The PBM database includes mail-service and community pharmacy claims. During the time period of this study, from January 1, 2002, through May 31, 2006, mailservice pharmacy accounted for $5 \%$ to $7 \%$ of all pharmacy claims and $15 \%$ to $23 \%$ of total net plan (payer) cost. Pharmacy claims are aggregated by date of service, and all resource utilization and costs are reported net of claim reversals and adjustments.

\section{Results}

Oral chemotherapy drugs represented approximately $0.27 \%$ of total drug benefit costs in 2002, rising in a nearly linear manner over a 5 -year period to $0.73 \%$ in 2006 (Figure 1). Net plan cost PMPM, after subtraction of member cost share, was approximately $\$ 0.08$ in 2002 and approximately $\$ 0.24$ PMPM in the first 5 months of 2006 (Figure 2). Due to dollar copayments as the predominant structure for member cost sharing in pharmacy benefit plans of small, self-insured employers during this time period and the relatively high cost for oral chemotherapy drugs, the average member cost share for oral chemotherapy drugs was about one third that for all drugs over this 4.5-year period Figure 3). In the first 5 months of 2006, the average member cost share for oral chemotherapy drugs was $6.9 \%$ for beneficiaries in pharmacy benefit plans sponsored by small employers versus an average $8.5 \%$ for the comparison insured health plan of similar total membership (data not shown).

Imatinib mesylate accounted for $45 \%$ of total spending on oral chemotherapy agents for small employers in 2002 versus 40\% in 2006 (Figure 4). Despite market availability for only a few months in 2006, erlotinib accounted for $18 \%$ of the net cost of oral chemotherapy drugs, followed by capecitabine at 14\%; among the other oral chemotherapy drugs, each accounted for less than $10 \%$ of total spending. The distribution of spending among the oral chemotherapy agents was similar for the insured health plan, with the exception of gefitinib which, unlike the small employers, had some utilization at 3\% of total spending (Figure 5), accounting for approximately $\$ 0.01$ PMPM (Table 2).

The actual price of the oral chemotherapy drugs in the first 5 months of 2006 is derived from the average allowed charge per day of therapy multiplied by 30 to obtain a standardized price per 30-day supply, prior to subtraction of the member cost share. Lenalidomide and sunitinib malate had the highest average allowed charge per 30-day supply, approximately $\$ 7,000$ for each (Figure 6). The average allowed charge per 30-day supply for the 3 highest-expenditure oral chemotherapy drugs was $\$ 3,015$ for imatinib mesylate, representing approximately $40 \%$ of total spending; $\$ 2,864$ for erlotinib (18\% of total spending); and $\$ 2,127$ for capecitabine ( $14 \%$ of total spending).

\section{Discussion}

Prior to the market introduction of capecitabine and imatinib, chemotherapy agents were either relatively low-cost oral drugs or injectable drugs. The relatively low-cost oral chemotherapy drugs included mercaptopurine (6-MP, Purinethol), and thioguanine, both approved before 1967. High-cost chemotherapy drugs such as trastuzumab (Herceptin; initially approved by the FDA on September 25, 199731), bevacizumab (Avastin; approved for metastatic colon cancer February 26, 2004), and cetuximab (Erbitux; approved for metastatic colon cancer, February 12, 2004) are available as injectable dosage forms only. All of these have had either indications added to their approved package labeling or will have in the near future.

While the present impact on outpatient pharmacy budgets is still relatively small, oral antineoplastic agents are associated 
with a host of attractive features that guarantee the commitment of research funding and market introduction of more oral agents. Obvious reasons for the preference of oral dose forms over injectable dose forms include ease of administration, patient preference, and lower risk of complications compared with injectable drugs, particularly intravenous administration. ${ }^{32}$ Less obvious reasons include the lower cost of administration, (e.g., the direct costs in medical professional time, medical supplies, and intravenous pumps) and the indirect costs associated with travel time to medical facilities and caregiver time. Oral agents may have fewer side effects with the possibility of improved tolerance and adherence to therapy. ${ }^{33}$ However, adherence to therapy is not necessarily assured with oral chemotherapy agents, ${ }^{34}$ and the cost of production is not necessarily lower. ${ }^{35}$

A drug like erlotinib, with an average charge per year of therapy of approximately $\$ 35,000$ for 1 patient and a net cost after member cost share of $\$ 34,000$ or more, can increase net pharmacy benefit costs by more than 15\%, or $\$ 5.67$ PMPM, for a small self-insured employer with 500 enrolled members. The matter of financial budget impact on a large health plan was posed by Ramsey et al. in mid-2006. ${ }^{30}$ The authors used a pharmacoeconomic model to predict the budget impact of erlotinib on a hypothetical third-party payer with 500,000 enrolled members. When used according to the FDA-approved label indications as second-line or third-line therapy for NSCLC, they estimated that the incremental cost of placing erlotinib on the drug formulary would be less than $\$ 0.01$ PMPM. This pharmacoeconomic work suggests a minimal and insignificant budget impact for a 500,000-member health plan. However, the actual cost effects could be different since (a) the assumed reductions in chemotherapy-related infusion costs may or may not be realized, and (b) costs associated with adverse events may be either over- or under-reported in the actual medical and pharmacy claims data.

From a silo-perspective in cost management, a predominant business perspective in 2006, including the focus on quarterly financial results for the enterprise and its individual departments and cost centers, the immediate effect on departmental (benefit) costs is important. This present research suggests that prior to consideration of potential offsetting costs, the direct drug benefit costs for erlotinib in 2006 are approximately $\$ 0.04$ PMPM, approximately 5 times higher than the cost identified in the research by Ramsey et al. This 5 -fold discrepancy suggests a need to validate the pharmacoeconomic modeling with actual health plan data for pharmacy and other medical costs.

The most likely source of the cost discrepancy is the focus by Ramsey et al. on only 1 of erlotinib's 2 approved indications. In ignoring erlotinib's approval for first-line treatment of patients with locally advanced, unresectable, or metastatic pancreatic cancer when used in combination with gemcitabine (Gemzar), ${ }^{36}$ the budget forecast model is not a budget forecast model for the drug but for the drug for a specific indication.

\begin{tabular}{l|c|c|c|c}
\hline \multicolumn{1}{c|}{ TABLE 2 } & $\begin{array}{c}\text { Pharmacy Benefit Costs for Oral } \\
\text { Chemotherapy Drugs in 2006* }\end{array}$ \\
\hline Generic Name & $\begin{array}{c}\text { Small Employers } \\
\text { PMPM (\$) }\end{array}$ & \% Total & $\begin{array}{c}\text { Insured Health Plan } \\
\text { PMPM (\$) }\end{array}$ & \% Total \\
\hline Imatinib mesylate & 0.10 & 40 & 0.12 & 30 \\
\hline Erlotinib & 0.04 & 18 & 0.09 & 21 \\
\hline Capecitabine & 0.03 & 14 & 0.07 & 16 \\
\hline Lenalidomide & 0.02 & 9 & 0.03 & 7 \\
\hline Sunitinib & 0.02 & 8 & 0.05 & 13 \\
\hline Sorafenib & 0.02 & 7 & 0.05 & 11 \\
\hline Gefitinib & 0.00 & 0 & 0.01 & 3 \\
\hline Mercaptopurine & 0.01 & 4 & NA & - \\
\hline Purinethol & $<0.01$ & $<1$ & NA & - \\
\hline Total & 0.24 & & 0.42 & \\
\hline
\end{tabular}

* These drugs are identified by Medi-Span Generic Product Indicator (GPI) beginning with 2153, or 9939 or 2130 (except not GPI beginning with 213000501 [methotrexate], which is standard treatment for several indications, including rheumatoid arthritis and psoriasis, in addition to use as an antineoplastic agent), for dates of service from January 1, 2006, through May 31, 2006. $N A=$ data not available; $P M P M=$ per member per month.

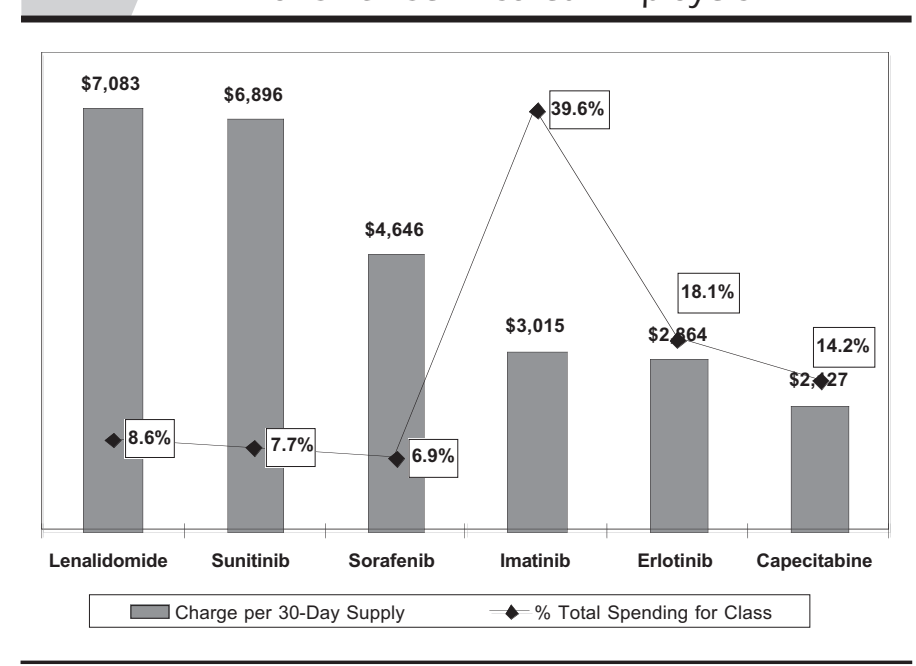

Allowed charge is discount pricing, comprising allowed ingredient cost and pharmacist professional fee, before subtraction of member cost share, for claims with dates of service in 2006 through May 31; from a PBM database for more than 2,000 small, self-insured employers.

PBM= pharmacy benefits manager. 
A portion of the cost difference could also be attributable to off-label use, a factor for erlotinib and the other oral chemotherapy agents as it is for all drugs. For erlotinib, off-label use includes treatment of squamous cell head and neck cancer.

\section{Limitations}

This analysis was intended to be descriptive, focusing on the direct financial effects of oral chemotherapy drugs on pharmacy benefit costs. Cost-benefit analysis was beyond the objective and scope of this research. Analysis of the cost per outcome is information that is needed. For example, one of the 2 clinical trials used to seek FDA approval for the multiple myeloma indication for lenalidomide showed that median time to progression of disease was increased approximately 17 weeks, from 19.9 weeks in the dexamethasone group to 37.1 weeks in the lenalidomide plus dexamethasone group. ${ }^{1}$ In addition to the drug cost in excess of $\$ 6,000$ per month, the cost in terms of side effects was large, with a greater proportion of patients experiencing serious side effects such as febrile neutropenia and deep vein thrombosis (DVT) in the lenalidomide + dexamethasone group compared with the dexamethasone group alone. The incidence of thrombotic events such as DVT, pulmonary embolism (PE), and intracranial venous sinus thrombosis was $12 \%$ in the lenalidomide + dexamethasone versus $4 \%$ in the dexamethasone group. The "black-box" warning on the label of lenalidomide includes the potential for birth defects; hematologic toxicity, including neutropenia and thrombocytopenia; and DVT and PE. ${ }^{37}$ Results in the willingness-to-pay research suggests that patients with NSCLC and healthy subjects are willing to pay a median of $\$ 100$ CAD per month of therapy with an oral epidermal growth factor receptor tyrosine kinase inhibitor such as erlotinib, ${ }^{38}$ less than $5 \%$ of the actual price of the drug in the present study.

Others have posed the question of the value of the outcomes obtained for the rapidly escalating cost of chemotherapy regimens. Schrag compared the costs of various drug therapy regimens for metastatic colorectal cancer following FDA approval in February 2004 of the monocolonal antibodies bevacizumab (Avastin, targeting vascular endothelial growth factor) and cetuximab (Erbitux, targeting epithelial growth factor receptor) for use in conjunction with cytotoxic drug regimens. ${ }^{39}$ Calculated at $95 \%$ of the average wholesale price in May 2004, 8 weeks of the Mayo Clinic regimen of monthly bolus of fluorouracil plus leucovorin cost $\$ 63$ versus $\$ 304$ for a weekly bolus of fluororacil plus leucovorin (Roswell Park regimen) or $\$ 263$ for biweekly fluorouracil plus leucovorin in a 48-hour infusion (LVSFU2 regimen). Adding either irinotecan (FOLFIRI) or oxaliplatin (FOLFOX) to LVSFU2 increased the initial 8-week cost to $\$ 9,381$ or $\$ 11,889$, respectively. The addition of bevacizumab to FOLFIRI or FOLFOX increased the 8-week cost in 2004 dollars to about $\$ 21,000$, and cetuximab added to either irinotecan or FOLFIRI resulted in an 8-week cost of approximately $\$ 30,700$. The numerator for the benefit-cost equation is in the context of 8 months median duration of survival without chemotherapy, 12 months with fluorouracil, and 21 months with FOLFIRI or FOLFOX regimens. The addition of either bevacizumab or cetuximab increased the average drug treatment cost to $\$ 161,000$ per patient, without evidence that median survival would at any additional time extend beyond the 21 months seen with FOLFIRI/FOLFOX.

The present research is representative only of small, selfinsured employers. While an insured health plan of similar-size membership had similar distribution of spending on oral chemotherapy drugs in 2006, the PMPM costs were $\$ 0.42$ versus $\$ 0.24$ for the group of small employers (PBM), including $\$ 0.01$ PMPM contributed by gefitinib, which had no utilization in the group of small employers. Health plans that manage pharmacy benefits more closely, such as the use of prior authorization interventions to ensure utilization of these drugs in accordance with FDA-approved indications or other treatment guidelines, will no doubt experience different costs.

\section{Conclusion}

The FDA approval of 5 oral drugs for chemotherapy indications in the 7-month period ended June 30, 2006, portends increased spending in outpatient pharmacy benefit plans. At mid-year 2006 , total spending is in the range of $\$ 0.24$ to $\$ 0.42$ PMPM for 2 different pharmacy benefit sponsors, excluding the additional costs of approximately $7 \%$ to $8 \%$ for member cost share. Imatinib mesylate accounted for 30\% to $40 \%$ of total spending for oral chemotherapy drugs in the first 5 months of 2006 .

\section{DISCLOSURES}

The author discloses no potential bias or conflict of interest relating to this article. This article reflects the work of the author and has received the same degree of peer-review scrutiny required of all articles published in the Journal of Managed Care Pharmacy. The author acknowledges the assistance of Alice C. Ceacareanu, $\mathrm{PhD}$, University of Tennessee, Memphis, in preparing summary comparison data for an insured health plan in the southern United States, and Jeannette Y. Wick, $\mathrm{RPh}, \mathrm{MBA}$, senior clinical research pharmacist, National Cancer Institute, Bethesda, Maryland, for her guidance and review of this article.

\section{REFERENCES}

1. U.S. Food and Drug Administration, Office of Oncology Drug Products (OODP). FDA approves lenalidomide oral capsules (Revlimid) for use in combination with dexamethasone in patients with multiple myeloma. Available at: http://www.fda.gov/cder/Offices/OODP/whatsnew/lenalidomide.htm. Accessed August 29, 2006.

2. Anand G. Celgene to price cancer medicine at $\$ 6,195$ a month. Wall Street Journal. July 1, 2006:A4.

3. Prescribing information from the product label for lenalidomide (Revlimid) reported in Drug Facts and Comparisons (Clinisphere version ISBN 1-57439036-8). St. Louis, MO: Wolters, Kluwer Health, Inc. August 2006. Accessed August 29, 2006.

4. U.S. Food and Drug Administration. FDA Talk Paper-FDA approves Xeloda for breast cancer. Available at: http://www.fda.gov/bbs/topics/ ANSWERS/ANS00864.html. Accessed August 30, 2006. 
5. McCann J. MAbs take spotlight at hematology meeting. Drug Top. January $15,2001: 45$

6. MedlinePlus. Medical encyclopedia. Chronic myelogenous leukemia (CML) Available at: http://www.nlm.nih.gov/medlineplus/ency/article/000570.htm. Accessed September 1, 2006.

7. Fuhrman V. Novartis seeks speedy approval of 'smart' cancer drug, Glivec. Wall Street Journal. March 1, 2001:B14.

8. Anonymous. FDA clears novel Novartis cancer drug. Wall Street Journal. May 11, 2001:A3.

9. Anonymous. FDA gives a green light to Gleevec cancer drug. Wall Street Journal. February 4, 2002:B5.

10. Gastrointestinal stromal tumor. Wikipedia. Available at: http://en.wikipedia.org/wiki/Gastrointestinal_stromal_tumor. Accessed September 1, 2006.

11. Antineoplastic agents, protein-tyrosine kinase inhibitors, imatinib mesylate. Drug Facts and Comparisons, Clinisphere version ISBN 1-57439-036-8), August 2006. St. Louis, MO: Wolters, Kluwer Health, Inc. Accessed September 1, 2006.

12. Antineoplastic agents, epidermal growth factor receptor inhibitors, gefitinib oral. Drug Facts and Comparisons, Clinisphere version ISBN 1-57439036-8, August 2006. St. Louis, MO: Wolters, Kluwer Health, Inc. Accessed August 29, 2006

13. U.S. Food and Drug Administration. Gefitinib (Iressa) product label, May 6, 2004 revision. Available at: http://www.fda.gov/cder/foi/label/2004/ 21399slr003_Iressa_lbl.pdf. Accessed Sept 2, 2006.

14. U.S. Food and Drug Administration. FDA Alert [June 2005]. Gefitinib (marketed as Iressa) information. Available at: http://www.fda.gov/cder/drug/ infopage/gefitinib/default.htm. Accessed September 2, 2006.

15. U.S. Food and Drug Administration. FDA News. FDA approves new drug for the most common type of lung cancer-drug shows survival benefit. November 19, 2004. Available at: http://www.fda.gov/bbs/topics/news/2004/ NEW01139.html. Accessed September 3, 2006.

16. Antineoplastic agents, epidermal growth factor receptor inhibitors, erlotinib oral. Drug Facts and Comparisons, Clinisphere version ISBN 157439-036-8, August 2006. St. Louis, MO: Wolters, Kluwer Health, Inc. Accessed September 3, 2006.

17. U.S. Food and Drug Administration. Oncology tools. Approved claims for 2005. Available at: http://www.accessdata.fda.gov/scripts/cder/onctools/ yearlistclaim.cfm?Approv_Date=2005. Accessed September 3, 2006

18. Shepherd FA, Rodrigues Pereira J, et al, for the National Cancer Institute of Canada Clinical Trials Group. Erlotinib in previously treated non-small-cell lung cancer. N Engl J Med. 2005;353:123-32.

19. U.S. Food and Drug Administration. FDA News. FDA approves new treatment for advanced kidney cancer. December 20, 2005. Available at: http://www.fda.gov/bbs/topics/NEWS/2005/NEW01282.html. Accessed September 3, 2006.

20. U.S. Food and Drug Administration. FDA News. FDA approves new treatment for gastrointestinal and kidney cancer. January 26, 2006. Available at: http://www.fda.gov/bbs/topics/news/2006/NEW01302.html. Accessed September 3, 2006.

21. Antineoplastic agents, multikinase inhibitor, sorafenib oral. Drug Facts and Comparisons, Clinisphere version ISBN 1-57439-036-8, August 2006. St. Louis, MO: Wolters, Kluwer Health, Inc. Accessed September 3, 2006.

22. Antineoplastic agents, protein-tyrosine kinase inhibitors, sunitinib malate oral. Drug Facts and Comparisons, Clinisphere version ISBN 1-57439-036-8, August 2006. St. Louis, MO: Wolters, Kluwer Health, Inc. Accessed September 3, 2006.

23. U.S. Food and Drug Administration. Office of Oncology Drug Products (OODP). FDA approves Thalomid (thalidomide) to treat multiple myeloma. Available at: http://www.fda.gov/cder/Offices/OODP/whatsnew/ thalidomide.htm. Accessed August 29, 2006.
24. U.S. Food and Drug Administration. Thalidomide information. FDA announces approval of drug for Hansen's Disease (leprosy) side effect: imposes unprecedented author to restrict distribution. Available at: http://www.fda.gov/ cder/news/thalinfo/default.htm. Accessed August 29, 2006.

25. Biologic and immunologic agents, immunomodulators, thalidomide oral. Drug Facts and Comparisons, Clinisphere version ISBN 1-57439-036-8, August 2006. St. Louis, MO: Wolters, Kluwer Health, Inc. Accessed August 29,2006

26. U.S. Food and Drug Administration. Office of Oncology Drug Products (OODP). FDA approves dasatinib (Sprycel) for use in the treatment of adults with chronic phase, accelerated phase, or myeloid or lymphoid blast phase chronic myeloid leukemia. Available at: http://www.fda.gov/cder/Offices/OODP/ whatsnew/dasatinib.htm. Accessed September 1, 2006.

27. Myelodysplastic syndrome. Leukemia Research Foundation. Available at: http://www.lrf.org.uk/en/l/infdispatmye.html. Accessed September 2, 2006.

28. Antineoplastic agents, DNA demethylation agents, azacitidine. Drug Facts and Comparisons, Clinisphere version ISBN 1-57439-036-8, August 2006. St. Louis, MO: Wolters, Kluwer Health, Inc. Accessed August 29, 2006.

29. Myelodysplastic Foundation. Facts you should know about Medicare Part D. Available at: http://www.mds-foundation.org/articles/medicare-factspart-d.htm\#facts. Accessed September 2, 2006.

30. Ramsey SD, Clarke L, Kamath TV, Lubeck D. Evaluation of erlotinib in advanced non-small cell lung cancer: impact on the budget of a U.S. health insurance plan. J Manag Care Pharm. 2006;12(6):472-78. Available at: http://www.amcp.org/data/jmcp/form_472-478.pdf. Accessed August 31, 2006

31. Antineoplastic agents, monoclonal antibodies, traztuzumab. Drug Facts and Comparisons, Clinisphere version ISBN 1-57439-036-8, August 2006. St. Louis, MO: Wolters, Kluwer Health, Inc. Accessed August 29, 2006.

32. Homberg M, Zanni GR. Bringing hope home with oral antineoplastic agents. Pharm Times. March 2005. Available at: https://secure.pharmacytimes.com/lessons/200503-02.asp. Accessed September 3, 2006.

33. Partridge AH, Avorn J, Wang PS, Winer EP. Adherence to therapy with oral antineoplastic agents. J Natl Cancer Inst. 2002;94(9):652-61.

34. O'Neill VJ, Twelves CJ. Oral cancer treatment: developments in chemotherapy and beyond. Br J Cancer. 2002;87(9):933-37.

35. Wick JY. Senior clinical research pharmacist, National Cancer Institute, Bethesda, MD [personal communication]

36. Antineoplastic agents, epidermal growth receptor factor inhibitors, erlotinib. Drug Facts and Comparisons, Clinisphere version ISBN 1-57439036-8, August 2006. St. Louis, MO: Wolters, Kluwer Health, Inc. Accessed August 29, 2006

37. Revlimid (lenalidomide) product label, $5 \mathrm{mg} 10 \mathrm{mg}, 15 \mathrm{mg}$, and $25 \mathrm{mg}$ capsules. U.S. Food and Drug Administration. Available at: http://www.fda.gov/ medwatch/safety/2006/Jun_PIs/Revlimid_PI.pdf. Accessed September 3, 2006.

38. Leight NB, Tsao WS, Zawuiza DL, Nematollahi M, Shepherd FA. A willingness-to-pay study of oral epidermal growth factor tyrosine kinase inhibitors in advanced non-small cell lung cancer. Lung Cancer. 2006;51(1):137-38.

39. Schrag D. The price tag on progress—chemotherapy for colorectal cancer. N Engl J Med. 2004;351:317-19. 